\title{
Ligament augmentation for prevention of proximal junctional kyphosis and proximal junctional failure in adult spinal deformity
}

\author{
${ }^{*}$ Michael M. Safaee, MD, ${ }^{1}$ Vedat Deviren, MD, ${ }^{2}$ Cecilia Dalle Ore, BA, ${ }^{1}$ Justin K. Scheer, MD, ${ }^{3}$ \\ Darryl Lau, MD, ${ }^{1}$ Joseph A. Osorio, MD, PhD, ${ }^{1}$ Fred Nicholls, MD, ${ }^{4}$ and Christopher P. Ames, MD ${ }^{1,2}$ \\ Departments of ${ }^{1}$ Neurological Surgery and ${ }^{2}$ Orthopedic Surgery, University of California, San Francisco, California; ${ }^{3}$ Department \\ of Neurological Surgery, University of Illinois, Chicago, Illinois; and ${ }^{4}$ Department of Orthopedic Surgery, University of Calgary, \\ Alberta, Canada
}

OBJECTIVE Proximal junctional kyphosis (PJK) is a well-recognized, yet incompletely defined, complication of adult spinal deformity surgery. There is no standardized definition for PJK, but most studies describe PJK as an increase in the proximal junctional angle (PJA) of greater than $10^{\circ}-20^{\circ}$. Ligament augmentation is a novel strategy for PJK reduction that provides strength to the upper instrumented vertebra (UIV) and adjacent segments while also reducing junctional stress at those levels.

METHODS In this study, ligament augmentation was used in a consecutive series of adult spinal deformity patients at a single institution. Patient demographics, including age; sex; indication for surgery; revision surgery; surgical approach; and use of 3-column osteotomies, vertebroplasty, or hook fixation at the UIV, were collected. The PJA was measured preoperatively and at last follow-up using 36 -inch radiographs. Data on change in PJA and need for revision surgery were collected. Univariate and multivariate analyses were performed to identify factors associated with change in PJA and proximal junctional failure (PJF), defined as PJK requiring surgical correction.

RESULTS A total of 200 consecutive patients were included: 100 patients before implementation of ligament augmentation and 100 patients after implementation of this technique. The mean age of the ligament augmentation cohort was 66 years, and $67 \%$ of patients were women. Over half of these cases (51\%) were revision surgeries, with $38 \%$ involving a combined anterior or lateral and posterior approach. The mean change in PJA was $6^{\circ}$ in the ligament augmentation group compared with $14^{\circ}$ in the control group $(p<0.001)$. Eighty-four patients had a change in PJA of less than $10^{\circ}$. In a multivariate linear regression model, age $(p=0.016)$, use of hook fixation at the UIV $(p=0.045)$, and use of ligament augmentation $(p<0.001)$ were associated with a change in PJA. In a separate model, only ligament augmentation (OR $0.193, p=0.012$ ) showed a significant association with PJF.

CONCLUSIONS Ligament augmentation represents a novel technique for the prevention of PJK and PJF. Compared with a well-matched historical cohort, ligament augmentation is associated with a significant decrease in PJK and PJF. These data support the implementation of ligament augmentation in surgery for adult spinal deformity, particularly in patients with a high risk of developing PJK and PJF.

https://thejns.org/doi/abs/10.3171/2017.9.SPINE1710

KEY WORDS proximal junctional kyphosis; proximal junctional failure; spinal deformity; ligament augmentation

$\mathrm{P}$ ROXIMAL junctional kyphosis (PJK) is a well-recognized, yet incompletely defined, complication in patients undergoing instrumented fusion for spinal deformity. The condition most commonly presents with abnormal kyphosis immediately above the upper instru- mented vertebra (UIV). The angle of kyphosis is measured using the sagittal Cobb angle between the inferior endplate of the UIV and superior endplate of the second vertebral body above the UIV (UIV+2). The definition of PJK varies in the literature, and some suggest that PJK

ABBREVIATIONS PJA = proximal junctional angle; PJF = proximal junctional failure; $\mathrm{PJK}=$ proximal junctional kyphosis; UIV = upper instrumented vertebra. SUBMITTED January 4, 2017. ACCEPTED September 19, 2017.

INCLUDE WHEN CITING Published online February 23, 2018; DOI: 10.3171/2017.9.SPINE1710.

* M.M.S. and V.D. contributed equally to this work. 
represents a spectrum including proximal junctional failure (PJF), which includes radiographic evidence of PJK as well as clinical sequelae, such as pain, neurological deficit, and impaired quality of life requiring revision surgery. ${ }^{8,24}$ Radiographic definitions of PJK generally require kyphosis greater than $10^{\circ}-20^{\circ}$ compared with the preoperative baseline, but there is no standardized definition. ${ }^{7,10,18}$ Some authors have attempted to create grading and classification scales for PJK. The Boachie-Adjei classification scheme for PJK is based on the type of structural failure (1, ligamentous; 2, bone; or 3, implant-bone interface), degree of kyphosis $\left(\mathrm{A}, 10^{\circ}-19^{\circ}\right.$; $\mathrm{B}, 20^{\circ}-29^{\circ}$; or $\mathrm{C}, \geq 30^{\circ}$ ), and the presence of spondylolisthesis $(\mathrm{N}$, absence of spondylolisthesis above the UIV; or S, presence of spondylolisthesis above the UIV). ${ }^{37}$ The PJF Severity Scale, developed by Hart et al. and the International Spine Study Group, includes neurological deficit ( 0 , none; 2 , radicular pain; or 4 , myelopathy/motor deficit), focal pain ( 0 , none; 1 , visual analog scale score $\leq 4$; or 3 , visual analog scale score $\geq 5$ ), problems with instrumentation $(0$, none; 1 , partial fixation loss or prominence; or 2, complete fixation loss), change in kyphosis or posterior ligamentous complex integrity $(0$, $0^{\circ}-10^{\circ} ; 1,>10^{\circ}$ to $20^{\circ}$; or $2,>20^{\circ}$ or posterior ligamentous complex failure), UIV/UIV+1 fracture ( 0 , none; 1 , compression fracture; 2, burst or Chance fracture; or 3, translation), and level of the UIV (0, thoracolumbar junction; or 1 , upper thoracic). ${ }^{6}$

The causes of PJK are not fully understood but are believed to include one or more of the following factors: age-related degeneration and deformity, disruption of the posterior ligamentous complex, vertebral fractures, instrumentation failure, degenerative disc disease, and facet violation. $., 2,7,24,28$ Additional risk factors include older age, ,14,17,26 increased preoperative sagittal imbalance, ${ }^{18,19,21,23,33,35,36}$ use of pedicle screws, ${ }^{10,18,19,33}$ greater curvature correction, 18,19,33 disruption of posterior intervertebral elements, $, 14,19,23$ and fusion to lower lumbar vertebrae or the sacrum. ${ }^{16,25,27,33,35,36}$ Rates of PJK vary based on the reported definition; however, most range from $17 \%$ to $39 \% .7,15-17,25,35,36$ Interestingly, most cases of PJK occur relatively early in the postoperative course; $66 \%$ are observed in the first 3 months and $80 \%$ within the first 18 months. 33,36

Ligament augmentation is a novel technique for PJK prevention that provides additional strength to the junction between the UIV and the level above (UIV+1). The ligament suture used in this procedure is strong and durable, yet flexible. The augmentation process itself is straightforward and safe and does not significantly increase operative time, thus making it a valuable adjunct for PJK prevention in adult spinal deformity.

\section{Methods \\ Data Collection}

A consecutive series of 200 adult spinal deformity patients undergoing instrumented fusion were included in this study: 100 before implementation of ligament augmentation and 100 after implementation of the technique. Surgeries were performed from 2010 to 2015 at a single institution by 2 surgeons (V.D. and C.P.A.). Patient demo- graphics, including age; sex; indication for surgery; number of levels fused; and use of vertebroplasty, hook fixation at the UIV, or 3-column osteotomy, were collected. The proximal junctional angle (PJA) was measured preoperatively and at the last follow-up on standing 36-inch radiographs. The difference in these values was defined as the change in PJA. Patients with neuromuscular or neurodegenerative disorders were excluded from analysis. Only patients with at least 6 months of follow-up data were included. Spinopelvic parameters, including pelvic incidence, pelvic tilt, lumbar lordosis, pelvic incidence-lumbar lordosis mismatch, sagittal vertical axis, sacral slope, and thoracic kyphosis, were measured on pre- and postoperative standing 36-inch radiographs. All activities were approved by the Committee on Human Research, our institutional review board.

\section{Ligament Augmentation}

The goal of ligament augmentation is to provide strength to the UIV, UIV+1, and UIV-1 levels and decreased junctional stress at those levels. A matchstick burr is used to drill through the center of the spinous process, and a soft sublaminar cable is passed through these holes in a mirrored fashion (Fig. 1). Two cables are used (one on each side) and are pulled tightly until the desired tension is achieved. The cables are then locked onto the rod using the supplied connectors. The spinous processes at these levels are loaded in slight extension to resist flexion at the terminal construct.

\section{Statistical Analysis}

Univariate analysis of continuous variables was performed using the Student t-test and analysis of categorical variables using the chi-square test. Multivariate analysis was performed using both linear regression and binary logistic regression. Variables were included in the multivariate model if they were found to demonstrate a statistically significant relationship or were known factors associated with PJK and PJF. For purposes of the multivariate analysis, the UIV was categorized as cervical, upper thoracic (T1-5), lower thoracic (T6-12), and lumbar. Statistical significance was defined as $p<0.05$. All analyses were performed using IBM SPSS (version 24, IBM Corp.).

\section{Results}

\section{Patient and Surgical Demographics}

One hundred patients who underwent ligament augmentation were included in this analysis. The mean age was 66 years (range $25-84$ years); there were 33 men and 67 women. Indications for surgery varied, with many patients having more than one diagnosis. These indications included scoliosis in 49 patients, sagittal imbalance in 43, flat back in 34, adjacent-segment disease in 14, PJF in 7, and degenerative disease in 3. Over half of the surgeries $(n=51)$ were revisions, and a combined anterior or lateral and posterior approach was used in 38 . The mean number of levels fused was 11 (range 4-18). The UIV was cervical in 1 case, upper thoracic (T1-5) in 42 cases, lower thoracic (T6-12) in 56 cases, and lumbar in 1 case. Three-column osteotomies were performed in 40 cases. Hook fixation 

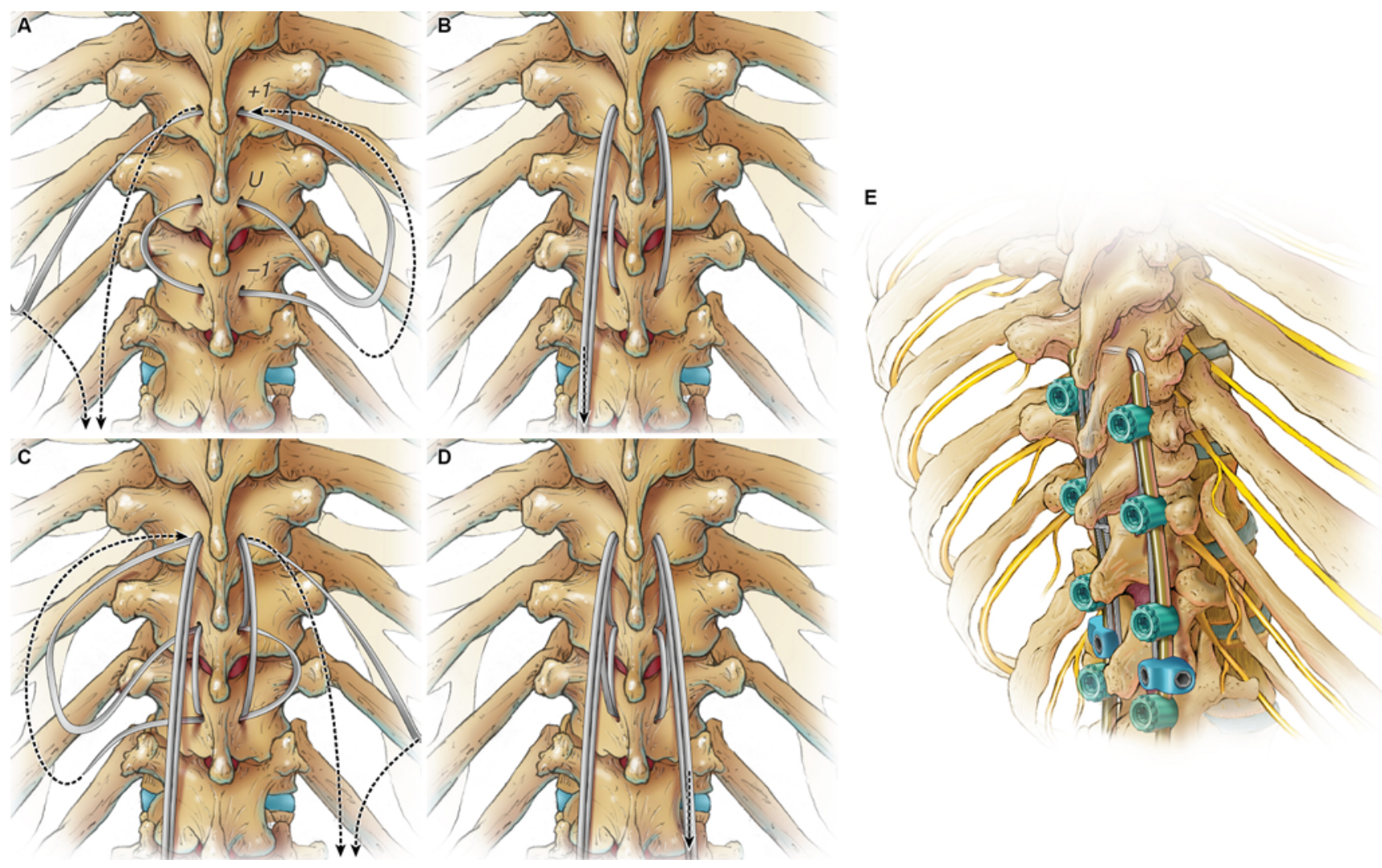

FIG. 1. Ligament augmentation. Using a matchstick burr, holes are drilled through the spinous processes of the UIV (U) and the levels immediately above (+1) and below (-1). A sublaminar cable is passed through each level in a stepwise fashion $(\mathbf{A})$ and is then pulled to 1 side $(\mathbf{B})$. The process is repeated with a second cable on the opposite side (C). This cable is then pulled down to obtain the desired amount of tension (D). The cables are locked onto the rods on each side using supplied connectors (E). Copyright University of California, San Francisco, courtesy of Kenneth Xavier Probst. Figure is available in color online only.

at the UIV was used in 42 cases and vertebroplasty in 48 cases. Demographics are summarized in Table 1.

\section{Surgical Outcomes}

PJA measurements were made preoperatively and at the last follow-up using standing 36-inch radiographs. The mean change in PJA was $6^{\circ} ; 84$ patients had a change of less than $10^{\circ}$. Twelve patients had a change in PJA of $10^{\circ}-$ $20^{\circ}$, and 4 patients had a change in PJA of greater than $20^{\circ}$ (Table 2). Compression fractures at the UIV were seen in 9 cases. Reoperation was performed in 19 cases; however, only 4 were for PJF. Other indications for revision surgery included iliac bolt removal $(n=4)$, pseudarthrosis $(n=3)$, wound complications $(n=3)$, correction of osteotomy $(n=$ 2 ), progression of deformity $(n=1)$, revision of a pedicle screw causing radiculopathy $(\mathrm{n}=1)$, and removal of a retained drain $(\mathrm{n}=1)$. The mean time to follow-up was 12 months (range 6-26 months). Surgical outcomes are summarized in Table 3.

\section{Comparison With Historical Cohort}

To assess the efficacy of ligament augmentation on the prevention of PJK and PJF, we compared this cohort with a consecutive series of 100 patients treated immediately before implementation of this strategy. The results are summarized in Table 4. The ligament augmentation co- hort was slightly older at 66 compared with 62 years $(\mathrm{p}$ $=0.014$ ). Both cohorts had a female preponderance, with no significant difference in sex distribution $(\mathrm{p}=0.541)$. Indications for surgery were not dramatically different, and rates of revision surgery $(\mathrm{p}=0.202)$ and combined anterior or lateral with posterior approach $(\mathrm{p}=0.771)$ were similar. Rates of 3-column osteotomy were similar ( $p=$ 0.318 ), and, although the mean number of levels fused was 11 in the ligament augmentation cohort compared with 10 in the historical cohort, this difference did meet statistical significance $(p=0.029)$. The ligament augmentation cohort had a higher rate of constructs with the UIV in the upper thoracic spine ( $42 \%$ vs $32 \%$ ), similar rates of constructs terminating at the lower thoracic spine (56\% each), and a lower rate of constructs terminating in the lumbar spine ( $1 \%$ vs $11 \%)$, a difference that was significant $(\mathrm{p}=$ 0.003 ). This increase in constructs terminating at the upper thoracic spine also explains the higher rate of hook fixation at the UIV in the ligament augmentation cohort ( $42 \%$ vs $18 \%, p<0.001)$. Rates of vertebroplasty were significantly higher in the ligament augmentation group (48\% vs 25\%); however, rates of compression fracture at the UIV were identical (9\%).

The mean change in PJA was $6^{\circ}$ in the ligament augmentation group compared with $14^{\circ}$ in the control group, a difference that was statistically significant $(\mathrm{p}<0.001)$. 
TABLE 1. Ligament augmentation cohort patient demographics

\begin{tabular}{lc}
\hline \multicolumn{1}{c}{ Variable } & Value \\
\hline Mean age in yrs (range) & $66(25-84)$ \\
Sex & 33 \\
Male & 67 \\
Female & \\
Indications for surgery & 49 \\
Scoliosis & 43 \\
Sagittal imbalance & 34 \\
Flat back & 14 \\
Adjacent-segment disease & 7 \\
PJF & 3 \\
Degenerative disease & 51 \\
\hline Revision surgery & \\
\hline Approach & 38 \\
Anterior or lateral \& posterior & 62 \\
Posterior only & \\
\hline Upper instrumented level & \\
Cervical & 1 \\
Upper thoracic & 42 \\
Lower thoracic & 56 \\
Lumbar & 1 \\
\hline 3-column osteotomy & 40 \\
\hline Hook fixation at UIV & 42 \\
\hline Vertebroplasty & 48 \\
\hline
\end{tabular}

Values are presented as the number of patients unless stated otherwise.

* Upper thoracic is defined as T1-5, and lower thoracic is defined as T6-12.

There were 4 cases of PJF in the ligament control group compared with 18 in the historical cohort, a difference that was also significant $(p=0.002)$. Other causes for reoperation included pseudarthrosis, iliac bolt removal, wound complications, progression of deformity, distal junctional failure, and osteotomy correction. There were 14 cases of reoperation for pseudarthrosis in the historical cohort and 3 in the ligament augmentation cohort, with notable differences $(\mathrm{p}=0.005)$, and 6 cases of progressive deformity in the historical cohort compared with 1 case in the ligament augmentation cohort $(\mathrm{p}=0.054)$. Spinopelvic parameters between the historical and ligament augmentation cohorts were compared, with no significant differences in pelvic incidence, pelvic tilt, lumbar lordosis, pelvic incidencelumbar lordosis mismatch, sagittal vertical axis, sacral slope, and thoracic kyphosis at either preoperative or postoperative time points (Table 5).

\section{Multivariate Analysis}

To control for multiple factors that may be associated with a change in PJA and progression to PJF, we per-

TABLE 2. Change in PJA in the ligament augmentation cohort

\begin{tabular}{cc}
\hline Change in PJA & No. of Patients \\
\hline$<10^{\circ}$ & 84 \\
\hline $10-20^{\circ}$ & 12 \\
$>20^{\circ}$ & 4 \\
\hline
\end{tabular}

TABLE 3. Surgical outcomes in the ligament augmentation cohort

\begin{tabular}{lc}
\hline \multicolumn{1}{c}{ Outcome Measure } & Value \\
\hline Mean change in PJA & $6^{\circ}$ \\
\hline Compression fractures at UIV & 9 \\
\hline Reop & 19 \\
PJF & 4 \\
Iliac bolt removal & 4 \\
Pseudarthrosis & 3 \\
Wound complication & 3 \\
Correction of osteotomy & 2 \\
Progression of deformity & 1 \\
Other & 2 \\
\hline Mean time to follow-up in mos (range) & $12(6-26)$ \\
\hline
\end{tabular}

Values are presented as the number of patients unless stated otherwise.

formed linear regression analysis for change in PJA and binary logistic regression for PJF. In each of these models, we included age, sex, UIV, hook fixation at the UIV, vertebroplasty, and ligament augmentation based on the results of our univariate analysis of known risk factors for PJK and PJF. Variables demonstrating a significant association with change in PJA included age $(\mathrm{p}=0.016)$, use of hook fixation at the UIV $(p=0.045)$, and ligament augmentation $(\mathrm{p}<0.001)$. The only variable with a significant association with PJF was use of ligament augmentation (OR $0.193,95 \%$ CI $0.053-0.701 ; p=0.012$ ). The results of these multivariate analyses are summarized in Tables 6 and 7.

\section{Discussion}

We present a novel strategy for the prevention of PJK and PJF. Ligament augmentation provides strength to the junction between the UIV and adjacent noninstrumented segment without significant violation of the facet joint, minimal blood loss, and only minor increase in the overall operative time. The ligament suture is made of a flexible material and provides both structural support and an element of lordotic tension as the spine is placed into final alignment. Over the past 5 years, our strategies for PJK prevention represent an evolution of techniques. We use hook fixation at the UIV for constructs terminating in the upper thoracic spine, since PJK at these levels is generally caused by soft-tissue fatigue. For constructs terminating in the lower thoracic spine, we have increased our use of vertebroplasty, since compression fractures at these levels often contribute to PJK. We also perform terminal contouring of rods in situ so that they are not forced into position with tension. Unlike the definite start time for our implementation of ligament augmentation, the use of hook fixation and vertebroplasty was introduced gradually. Therefore, to control for changes in technique over time, we performed a multivariate analysis to assess the relative contribution of each intervention. The results of that analysis showed that age, use of hook fixation, and ligament augmentation were associated with a change in PJA, but only ligament augmentation was associated with lower rates of PJF, which we define as PJK requiring surgical revision.

In this study, we present quantitative measurements of 
TABLE 4. Comparison of cohort demographics before and after implementation of ligament augmentation

\begin{tabular}{|c|c|c|c|}
\hline Variable & $\begin{array}{c}\text { Pre-Ligament } \\
\text { Augmentation } \\
\text { Cohort }\end{array}$ & $\begin{array}{c}\text { Ligament } \\
\text { Augmentation } \\
\text { Cohort }\end{array}$ & $\begin{array}{c}p \\
\text { Value }\end{array}$ \\
\hline No. of patients & 100 & 100 & \\
\hline Mean age in yrs & 62 & 66 & 0.014 \\
\hline $\begin{array}{l}\text { Sex } \\
\quad \text { Male } \\
\text { Female }\end{array}$ & $\begin{array}{l}29 \\
71\end{array}$ & $\begin{array}{l}33 \\
67\end{array}$ & 0.541 \\
\hline \multicolumn{4}{|l|}{ Indication for surgery } \\
\hline $\begin{array}{l}\text { Scoliosis } \\
\text { Sagittal imbalance } \\
\text { Flat back } \\
\text { Adjacent-segment disease } \\
\text { PJK } \\
\text { Degenerative disc disease }\end{array}$ & $\begin{array}{r}43 \\
42 \\
22 \\
18 \\
5 \\
8\end{array}$ & $\begin{array}{r}49 \\
43 \\
34 \\
14 \\
7 \\
3\end{array}$ & $\begin{array}{l}0.395 \\
0.886 \\
0.059 \\
0.440 \\
0.552 \\
0.121\end{array}$ \\
\hline Revision surgery & 58 & 49 & 0.202 \\
\hline $\begin{array}{l}\text { Combined anterior or lateral } \\
\quad \& \text { posterior }\end{array}$ & 36 & 38 & 0.771 \\
\hline No. of levels fused & 10 & 11 & 0.029 \\
\hline 3-column osteotomy & 47 & 40 & 0.318 \\
\hline \multicolumn{4}{|l|}{ Upper instrumented level* } \\
\hline Cervical & 1 & 1 & $>0.99$ \\
\hline Upper thoracic & 32 & 42 & 0.143 \\
\hline Lower thoracic & 56 & 56 & $>0.99$ \\
\hline Lumbar & 11 & 1 & 0.003 \\
\hline Pelvic fixation & 97 & 99 & 0.312 \\
\hline Hook fixation at UIV & 18 & 42 & $<0.001$ \\
\hline Vertebroplasty & 25 & 48 & 0.001 \\
\hline Fracture at UIV & 9 & 9 & $>0.99$ \\
\hline Change in PJA & $14^{\circ}$ & $6^{\circ}$ & $<0.001$ \\
\hline PJF & 18 & 4 & 0.002 \\
\hline \multicolumn{4}{|l|}{ Other causes for reop } \\
\hline Pseudarthrosis & 14 & 3 & 0.005 \\
\hline Iliac bolt removal & 2 & 4 & 0.407 \\
\hline Wound complications & 7 & 3 & 0.194 \\
\hline Progression of deformity & 6 & 1 & 0.054 \\
\hline Distal junctional failure & 2 & 0 & 0.115 \\
\hline Osteotomy correction & 2 & 2 & $>0.99$ \\
\hline Other & 0 & 2 & 0.155 \\
\hline
\end{tabular}

Values are presented as the number of patients unless stated otherwise.

* Upper thoracic is defined as T1-5, and lower thoracic is defined as T6-12.

the change in PJA, which allows for a more nuanced assessment of proximal junctional change. This is critical, particularly for patients with adult spinal deformity and even more so for those undergoing 3-column spinal osteotomies, since there are data showing that these osteotomies result in reciprocal changes in unfused segments, most notably an increase in the unfused thoracic kyphosis of $+13^{\circ} .^{20}$ These reciprocal changes must be considered in future studies assessing PJK and PJF. Since definitions of PJK are variable, we propose a more standardized metric by reporting the change in PJA since it more directly assesses biomechanical changes at the junction between the UIV and adjacent unfused segments.
TABLE 5. Comparison of spinopelvic parameters before and after implementation of ligament augmentation

\begin{tabular}{lccc}
\hline \multicolumn{1}{c}{ Variable } & $\begin{array}{c}\text { Pre-Ligament } \\
\text { Augmentation } \\
\text { Cohort }\end{array}$ & $\begin{array}{c}\text { Ligament } \\
\text { Augmentation } \\
\text { Cohort }\end{array}$ & $\begin{array}{c}\mathrm{p} \\
\text { Value }\end{array}$ \\
\hline No. of patients & 100 & 100 & \\
\hline Preop & 58 & 57 & 0.561 \\
Pelvic incidence & 26 & 26 & 0.938 \\
Pelvic tilt & 34 & 33 & 0.594 \\
Lumbar lordosis & 24 & 25 & 0.471 \\
PI-LL mismatch & 7.7 & 8.6 & 0.346 \\
SVA in cm & 33 & 31 & 0.268 \\
Sacral slope & 27 & 28 & 0.764 \\
Thoracic kyphosis & & & \\
\hline Postop & 58 & 56 & 0.243 \\
Pelvic incidence & 21 & 20 & 0.175 \\
Pelvic tilt & 49 & 51 & 0.316 \\
Lumbar lordosis & 13 & 12 & 0.434 \\
PI-LL mismatch & 4.2 & 3.9 & 0.715 \\
SVA in cm & 37 & 36 & 0.321 \\
Sacral slope & 36 & 40 & 0.091 \\
\hline Thoracic kyphosis & &
\end{tabular}

Values are presented as the number of patients unless stated otherwise.

$\mathrm{PI}-\mathrm{LL}=$ pelvic incidence-lumbar lordosis; SVA = sagittal vertical axis.

Given the increase in adults undergoing surgery for spinal deformity, there has been considerable investigation interest in PJK prevention strategies. Revision surgery for PJK and PJF presents a significant economic impact in adult spinal deformity; reducing these rates has the potential for significant cost savings. ${ }^{29}$ Additional techniques believed to reduce the risk of PJK include extending fusion constructs to include levels with baseline segmental kyphosis of more than $5^{\circ}$, using composite metals with greater flexibility, minimizing the destruction of soft tissue at the UIV, achieving optimal spinal balance and alignment postoperatively, and using transition rods. ${ }^{2,4,5,7,21,23}$ Vertebral cement augmentation, including vertebroplasty and kyphoplasty, is frequently used to provide additional strength to the superior segments of long spinal fusions, thus preventing vertebral body collapse and PJK. The biomechanics of this technique have been well studied in cadaveric models. ${ }^{11,12}$ Kayanja et al. compared stiffness and construct strength after augmenting between 0 and 3 vertebral levels with polymethylmethacrylate cement and found that these variables were not dependent on the number of augmented levels but rather on bone mineral density, and

TABLE 6. Multivariate analysis for change in PJA

\begin{tabular}{lcr}
\hline \multicolumn{1}{c}{ Variable } & \multicolumn{1}{c}{ B Coefficient } & p Value \\
\hline Age & $0.166(0.032$ to 0.301$)$ & 0.016 \\
\hline Male sex & $-1.583(-4.536$ to 1.371$)$ & 0.292 \\
\hline UIV & $-1.809(-4.933$ to 1.315$)$ & 0.255 \\
\hline Hook fixation at UIV & $-4.450(-8.800$ to -0.101$)$ & 0.045 \\
\hline Vertebroplasty & $0.871(-2.547$ to 4.289$)$ & 0.616 \\
\hline Ligament augmentation & $-7.879(-10.956$ to -4.802$)$ & $<0.001$ \\
\hline
\end{tabular}


TABLE 7. Multivariate analysis for PJF

\begin{tabular}{llc}
\hline \multicolumn{1}{c}{ Variable } & \multicolumn{1}{c}{ OR $(95 \% \mathrm{Cl})$} & p Value \\
\hline Age & $1.027(0.974-1.083)$ & 0.321 \\
\hline Male sex & $0.308(0.081-1.155)$ & 0.083 \\
\hline UIV & $6.273(0.208-189.122)$ & 0.291 \\
$\quad$ Cervical & $0.164(0.021-1.245$ & 0.080 \\
$\quad$ Upper thoracic & $0.445(0.094-2.099)$ & 0.306 \\
$\quad$ Lower thoracic & Reference & \\
$\quad$ Lumbar & $0.168(0.011-2.590)$ & 0.201 \\
\hline Hook fixation at UIV & $1.22(0.356-4.177)$ & 0.751 \\
\hline Vertebroplasty & $0.193(0.053-0.701)$ & 0.012 \\
\hline Ligament augmentation & &
\end{tabular}

that cement augmentation should be performed at the levels at highest risk for fracture. ${ }^{11}$ Furthermore, Kebaish et al. found that prophylactic vertebroplasty at the UIV and superior adjacent vertebrae reduced junctional fractures after long segment instrumentation. ${ }^{12}$ Although strengthening vertebral bodies has compelling biomechanical rationale, there are limitations to this technique. Cement augmentation can reduce nutrient supply to the adjacent intervertebral discs, thereby accelerating degenerative disease. ${ }^{32} \mathrm{Al}-$ tering the mechanics of load transfer with this technique also has the potential to cause fractures and subsequent collapse of adjacent levels; ${ }^{34}$ some have reported rates of new adjacent and nonadjacent fractures to be as high as $20 \% .{ }^{31}$ In our ligament augmentation cohort, the rate of vertebroplasty was significantly higher than that for the historical control group, but rates of compression fracture at the UIV remained identical.

The use of spinal hooks in lieu of pedicle screws at the UIV is another well-recognized PJK prevention strategy. Hooks provide a theoretical advantage since they require less violation of the facet joint and provide more dynamic fixation at the top of the construct. ${ }^{10,13,18}$ Several studies have compared PJK rates in patients with spinal hooks to those with pedicle screws at the UIV. Rates of PJK in pedicle screw constructs ranged from $30 \%$ to $35 \%$ compared with $0 \%$ to $30 \%$ in those with hooks at the UIV. ${ }^{10,18}$ There are obvious limitations to these studies, and more conclusive studies are needed. Vertical expandable prosthetic titanium rib implants have been described; however, their use is generally limited to cases of pediatric scoliosis. $\mathrm{Li}$ et al. reported PJK rates of $6 \%$ at 1 year; however, their definition limited PJK to cases with kyphosis greater than $25^{\circ} .22$ Other studies have reported rates of $22 \%-38 \%$, which are more consistent with historically reported rates of PJK. ${ }^{9,30}$ There are no data assessing PJK rates with the use of vertical expandable prosthetic titanium rib implants in adults.

There are several limitations to this study, most notably its modest follow-up and retrospective design. Future studies will include longer follow-up, but we believe it is important to note that most cases of PJK occur within 6 months from surgery. ${ }^{33,36}$ There is heterogeneity in our cohort with respect to the indications for surgery, although none of these differences were statistically significant. It is important to note that nearly half of the patients included had previously undergone surgery. The ligament augmentation cohort contained a higher proportion of ancillary techniques used for PJK prevention, specifically hook fixation and vertebroplasty, but increased rates of hook fixation were driven by a higher number of constructs terminating in the upper thoracic spine since we use hook fixation at those levels. Rates of vertebroplasty were also higher; however, interestingly, there was no difference in the rate of compression fractures at the UIV with the use of this technique. To control for differences in rates of hook fixation and vertebroplasty between cohorts, we performed multivariate analysis, which showed a strong association between ligament augmentation and reductions in changes in PJA and PJF. Despite the aforementioned limitations, the mean change in PJA of $6^{\circ}$ in the ligament augmentation group represents a dramatic improvement compared with the reported literature and our own historical controls. This reduction is also associated with a significant reduction in PJF, which has the potential for significant cost savings. ${ }^{29}$ Our results provide a compelling rationale for the use of ligament augmentation in high-risk adult spinal deformity cases and revision operations. We also believe that future studies should report magnitude of PJK in the form of change in PJA to allow for more standardized and reliable comparison of PJK prevention strategies.

\section{Conclusions}

PJK is a well-reported, yet incompletely defined, complication of surgery for adult spinal deformity. Published rates of PJK range from approximately $20 \%$ to $40 \%$, but definitions vary widely. In this single-institution study, we have provided data illustrating a dramatic reduction in PJK and PJF associated with the use of ligament augmentation in adult patients compared with historical controls undergoing spinal deformity surgery. Age, hook fixation at the UIV, and ligament augmentation were associated with changes in PJA in a multivariate model. In a similar model assessing the effect of these variables on PJF, only ligament augmentation was associated with a significant reduction in PJF. These results provide a compelling rationale for the implementation of ligament augmentation, but also stress the importance of standardized metrics for reporting PJK and PJF. Rather than arbitrary definitions for PJK, such as a PJA of greater than $10^{\circ}-20^{\circ}$, the magnitude of change, defined as the change in PJA, should become standard in future studies investigating PJK and PJF reduction strategies to allow for more reliable analysis across studies. Prospective studies must be pursued to determine the ultimate efficacy of ligament augmentation in adult spinal deformity.

\section{References}

1. Anderson AL, McIff TE, Asher MA, Burton DC, Glattes RC: The effect of posterior thoracic spine anatomical structures on motion segment flexion stiffness. Spine (Phila Pa 1976) 34:441-446, 2009

2. Arlet V, Aebi M: Junctional spinal disorders in operated adult spinal deformities: present understanding and future perspectives. Eur Spine J 22 (Suppl 2):S276-S295, 2013

3. Bridwell KH, Lenke LG, Cho SK, Pahys JM, Zebala LP, 
Dorward IG, et al: Proximal junctional kyphosis in primary adult deformity surgery: evaluation of 20 degrees as a critical angle. Neurosurgery 72:899-906, 2013

4. Cammarata M, Aubin CE, Wang X, Mac-Thiong JM: Biomechanical risk factors for proximal junctional kyphosis: a detailed numerical analysis of surgical instrumentation variables. Spine (Phila Pa 1976) 39:E500-E507, 2014

5. Denis F, Sun EC, Winter RB: Incidence and risk factors for proximal and distal junctional kyphosis following surgical treatment for Scheuermann kyphosis: minimum five-year follow-up. Spine (Phila Pa 1976) 34:E729-E734, 2009

6. Fu KMG, Hart R, Bess S, Burton DC, Shaffrey CI, Protopsaltis T, et al: Proximal junctional failure (PJF) classification and severity scale: development and validation of a standardized system. Neurosurg Focus 34(3):A22, 2013 (Abstract)

7. Glattes RC, Bridwell KH, Lenke LG, Kim YJ, Rinella A, Edwards C II: Proximal junctional kyphosis in adult spinal deformity following long instrumented posterior spinal fusion: incidence, outcomes, and risk factor analysis. Spine (Phila Pa 1976) 30:1643-1649, 2005

8. Hart RA, McCarthy I, Ames CP, Shaffrey CI, Hamilton DK, Hostin R: Proximal junctional kyphosis and proximal junctional failure. Neurosurg Clin N Am 24:213-218, 2013

9. Hasler CC, Mehrkens A, Hefti F: Efficacy and safety of VEPTR instrumentation for progressive spine deformities in young children without rib fusions. Eur Spine J 19:400408, 2010

10. Helgeson MD, Shah SA, Newton PO, Clements DH III, Betz RR, Marks MC, et al: Evaluation of proximal junctional kyphosis in adolescent idiopathic scoliosis following pedicle screw, hook, or hybrid instrumentation. Spine (Phila Pa 1976) 35:177-181, 2010

11. Kayanja MM, Schlenk R, Togawa D, Ferrara L, Lieberman I: The biomechanics of 1,2, and 3 levels of vertebral augmentation with polymethylmethacrylate in multilevel spinal segments. Spine (Phila Pa 1976) 31:769-774, 2006

12. Kebaish KM, Martin CT, O’Brien JR, LaMotta IE, Voros GD, Belkoff SM: Use of vertebroplasty to prevent proximal junctional fractures in adult deformity surgery: a biomechanical cadaveric study. Spine J 13:1897-1903, 2013

13. Kim HJ, Bridwell KH, Lenke LG, Park MS, Ahmad A, Song $\mathrm{KS}$, et al: Proximal junctional kyphosis results in inferior SRS pain subscores in adult deformity patients. Spine (Phila Pa 1976) 38:896-901, 2013

14. Kim HJ, Bridwell KH, Lenke LG, Park MS, Song KS, Piyaskulkaew C, et al: Patients with proximal junctional kyphosis requiring revision surgery have higher postoperative lumbar lordosis and larger sagittal balance corrections. Spine (Phila Pa 1976) 39:E576-E580, 2014

15. Kim HJ, Lenke LG, Shaffrey CI, Van Alstyne EM, Skelly AC: Proximal junctional kyphosis as a distinct form of adjacent segment pathology after spinal deformity surgery: a systematic review. Spine (Phila Pa 1976) 37 (22 Suppl):S144S164, 2012

16. Kim HJ, Yagi M, Nyugen J, Cunningham ME, Boachie-Adjei $\mathrm{O}$ : Combined anterior-posterior surgery is the most important risk factor for developing proximal junctional kyphosis in idiopathic scoliosis. Clin Orthop Relat Res 470:1633-1639, 2012

17. Kim YJ, Bridwell KH, Lenke LG, Glattes CR, Rhim S, Cheh G: Proximal junctional kyphosis in adult spinal deformity after segmental posterior spinal instrumentation and fusion: minimum five-year follow-up. Spine (Phila Pa 1976) 33:2179-2184, 2008

18. Kim YJ, Bridwell KH, Lenke LG, Kim J, Cho SK: Proximal junctional kyphosis in adolescent idiopathic scoliosis following segmental posterior spinal instrumentation and fusion: minimum 5-year follow-up. Spine (Phila Pa 1976) 30:20452050, 2005
19. Kim YJ, Lenke LG, Bridwell KH, Kim J, Cho SK, Cheh G, et al: Proximal junctional kyphosis in adolescent idiopathic scoliosis after 3 different types of posterior segmental spinal instrumentation and fusions: incidence and risk factor analysis of 410 cases. Spine (Phila Pa 1976) 32:2731-2738, 2007

20. Klineberg E, Schwab F, Ames C, Hostin R, Bess S, Smith JS, et al: Acute reciprocal changes distant from the site of spinal osteotomies affect global postoperative alignment. Adv Orthop 2011:415946, 2011

21. Lee GA, Betz RR, Clements DH III, Huss GK: Proximal kyphosis after posterior spinal fusion in patients with idiopathic scoliosis. Spine (Phila Pa 1976) 24:795-799, 1999

22. Li Y, Gold M, Karlin L: Proximal junctional kyphosis after vertical expandable prosthetic titanium rib insertion. Spine Deform 1:425-433, 2013

23. Maruo K, Ha Y, Inoue S, Samuel S, Okada E, Hu SS, et al: Predictive factors for proximal junctional kyphosis in long fusions to the sacrum in adult spinal deformity. Spine (Phila Pa 1976) 38:E1469-E1476, 2013

24. McClendon J Jr, O’Shaughnessy BA, Sugrue PA, Neal CJ, Acosta FL Jr, Koski TR, et al: Techniques for operative correction of proximal junctional kyphosis of the upper thoracic spine. Spine (Phila Pa 1976) 37:292-303, 2012

25. Mendoza-Lattes S, Ries Z, Gao Y, Weinstein SL: Proximal junctional kyphosis in adult reconstructive spine surgery results from incomplete restoration of the lumbar lordosis relative to the magnitude of the thoracic kyphosis. Iowa Orthop J 31:199-206, 2011

26. O'Leary PT, Bridwell KH, Lenke LG, Good CR, Pichelmann MA, Buchowski JM, et al: Risk factors and outcomes for catastrophic failures at the top of long pedicle screw constructs: a matched cohort analysis performed at a single center. Spine (Phila Pa 1976) 34:2134-2139, 2009

27. O'Shaughnessy BA, Bridwell KH, Lenke LG, Cho W, Baldus C, Chang MS, et al: Does a long-fusion "T3-sacrum" portend a worse outcome than a short-fusion "T10-sacrum" in primary surgery for adult scoliosis? Spine (Phila Pa 1976) 37:884-890, 2012

28. Oxland TR, Panjabi MM, Southern EP, Duranceau JS: An anatomic basis for spinal instability: a porcine trauma model. J Orthop Res 9:452-462, 1991

29. Theologis AA, Miller L, Callahan M, Lau D, Zygourakis C, Scheer JK, et al: Economic impact of revision surgery for proximal junctional failure after adult spinal deformity surgery: a cost analysis of 57 operations in a 10-year experience at a major deformity center. Spine (Phila Pa 1976) 41:E964E972, 2016

30. Thompson GH, Akbarnia BA, Campbell RM Jr: Growing rod techniques in early-onset scoliosis. J Pediatr Orthop 27:354-361, 2007

31. Trout AT, Kallmes DF, Kaufmann TJ: New fractures after vertebroplasty: adjacent fractures occur significantly sooner. AJNR Am J Neuroradiol 27:217-223, 2006

32. Verlaan JJ, Oner FC, Slootweg PJ, Verbout AJ, Dhert WJ: Histologic changes after vertebroplasty. J Bone Joint Surg Am 86-A:1230-1238, 2004

33. Wang J, Zhao Y, Shen B, Wang C, Li M: Risk factor analysis of proximal junctional kyphosis after posterior fusion in patients with idiopathic scoliosis. Injury 41:415-420, 2010

34. Watanabe K, Lenke LG, Bridwell KH, Kim YJ, Koester L, Hensley M: Proximal junctional vertebral fracture in adults after spinal deformity surgery using pedicle screw constructs: analysis of morphological features. Spine (Phila Pa 1976) 35:138-145, 2010

35. Yagi M, Akilah KB, Boachie-Adjei O: Incidence, risk factors and classification of proximal junctional kyphosis: surgical outcomes review of adult idiopathic scoliosis. Spine (Phila Pa 1976) 36:E60-E68, 2011 
36. Yagi M, King AB, Boachie-Adjei O: Incidence, risk factors, and natural course of proximal junctional kyphosis: surgical outcomes review of adult idiopathic scoliosis. Minimum 5 years of follow-up. Spine (Phila Pa 1976) 37:1479-1489, 2012

37. Yagi M, Rahm M, Gaines R, Maziad A, Ross T, Kim HJ, et al: Characterization and surgical outcomes of proximal junctional failure in surgically treated patients with adult spinal deformity. Spine (Phila Pa 1976) 39:E607-E614, 2014

\section{Disclosures}

Dr. Deviren: consultant for NuVasive, Guidepoint, Medicrea, Seaspine, and Biomet. Dr. Ames: employee of UCSF; consultant for
DePuy Synthes, Medtronic, Stryker, and Medicrea; and royalties from K2M, Stryker, Biomet Spine, DePuy Synthes, and NuVasive.

\section{Author Contributions}

Conception and design: Safaee, Deviren, Ames. Acquisition of data: Safaee, Dalle-Ore, Scheer, Lau, Osorio, Nicholls, Ames. Analysis and interpretation of data: Safaee, Deviren, Scheer, Lau, Osorio, Nicholls, Ames. Drafting the article: Safaee, Ames. Critically revising the article: all authors. Reviewed submitted version of manuscript: Safaee, Deviren. Approved the final version of the manuscript on behalf of all authors: Safaee. Statistical analysis: Safaee, Ames. Administrative/technical/material support: Deviren, Ames. Study supervision: Deviren, Ames.

\section{Correspondence}

Michael Safaee: University of California, San Francisco, CA. michael.safaee@ucsf.edu. 